M.J. Przydzial

I.D. Pogozheva

K.E. Bosse

S.M. Andrews

T.A. Tharp

J.R. Traynor

H.I. Mosberg

\section{Roles of residues 3 and 4 in cyclic tetrapeptide ligand recognition by the $\kappa$-opioid receptor}

\section{Authors' affiliations:}

M.J. Przydzial, I.D. Pogozheva and H.I. Mosberg, Department of Medicinal Chemistry, University of Michigan, Ann Arbor, MI 48109, USA

K.E. Bosse, S.M. Andrews, T.A. Tharp and I.R. Traynor, Department of Pharmacology, University of Michigan, Ann Arbor, MI 48109, USA

\section{Correspondence to:}

H.I. Mosberg

Department of Medicinal Chemistry

College of Pharmacy

University of Michigan

Ann Arbor

MI 48109-1065

USA

Tel.: (734) 764-8117

Fax: (734) 763-5595

E-mail: him@umich.edu

\section{Dates:}

Received 28 October 2004

Revised 15 November 2004

Accepted 27 November 2004

To cite this article:

Przydzial M.J., Pogozheva I.D., Bosse K.E., Andrews S.M., Tharp T.A., Traynor J.R. @) Mosberg H.I. Roles of residues 3 and 4 in cyclic tetrapeptide ligand recognition by the $\kappa$-opioid receptor.

J. Peptide Res., 2005, 65, 333-342.

DOI 10.1111/j.1399-3011.2005.00220.x

Copyright Blackwell Munksgaard, 2005
Key words: cyclic peptides; G protein-coupled receptor; $\kappa$-opioid receptor; opioid ligands

Abstract: A series of cyclic, disulfide- or dithioether-containing tetrapeptides based on previously reported potent $\mu$ - and $\delta$-selective analogs has been explored with the aim of improving their poor affinity to the $\kappa$-opioid receptor. Specifically targeted were modifications of tetrapeptide residues 3 and 4, as they presumably interact with residues from transmembrane helices 6 and 7 and extracellular loop 3 that differ among the three receptors. Accordingly, tetrapeptides were synthesized with Phe $^{3}$ replaced by aliphatic (Gly, Ala, Aib, Cha), basic (Lys, Arg, homoArg), or aromatic sides chains (Trp, Tyr, $p-\mathrm{NH}_{2} \mathrm{Phe}$ ), and with D-Pen ${ }^{4}$ replaced by $D-C y s^{4}$, and binding affinities to stably expressed $\mu-, \delta-$, and $\kappa$-receptors were determined. In general, the resulting analogs failed to exhibit appreciable affinity for the $\kappa$-receptor, with the exception of the tetrapeptide Tyr-c[D-Cys-Phe-D-Cys]-NH $\mathrm{N}_{2}$, cyclized via a disulfide bond, which demonstrated high binding affinity toward all opioid receptors $\left(\mathrm{Ki}^{\mu}=1.26 \mathrm{~nm}, \mathrm{Ki}^{\delta}=16.1 \mathrm{~nm}\right.$, $\left.\mathrm{Ki}^{\kappa}=38.7 \mathrm{~nm}\right)$. Modeling of the $\kappa$-receptor/ligand complex in the active state reveals that the receptor-binding pocket for residues 3 and 4 of the tetrapeptide ligands is smaller than that in the $\mu$-receptor and requires, for optimal fit, that the tripeptide cycle of the ligand assume a higher energy conformation. The magnitude of this energy penalty depends on the nature of the fourth residue of the peptide (D-Pen or D-Cys) and correlates well with the observed $\kappa$-receptor binding affinity.

Abbreviations: Aib, $\alpha$-aminoisobutyric acid; Cha, cyclohexylalanine; RP-HPLC, reverse-phase high-performance liquid chromatography; CHO, Chinese hamster ovary; TM, transmembrane $\alpha$-helix; EL, extracellular loop. 


\section{Introduction}

The cloned human $\mu-, \delta$-, and $\kappa$-opioid receptors $(1,2)$ belong to the G protein-coupled receptor (GPCR) superfamily of seven helical transmembrane proteins that mediate the actions of a majority of hormones and neurotransmitters $(3)$ and serve as the targets for $\sim 50 \%$ of marketed drugs (4). Binding of opioids to their receptors activates $\mathrm{G}_{\mathrm{i}} / \mathrm{o}$ proteins and leads to subsequent inhibition of adenylate cyclase, regulation of ion-channels, and activation of mitogenactivated protein (MAP) kinases, which in turn produce complex physiologic responses (5).

An understanding of the mechanism by which ligands bind to and activate their receptors requires knowledge of the three-dimensional structure of the receptors with bound ligand, however, for GPCRs, such precise experimental information is only available for rhodopsin in its inactive state $(6,7)$. In the absence of crystallographic structures of receptor-ligand complexes, two complementary approaches can be applied to uncover the molecular details of receptorligand interactions. The first approach is directed toward the determination of the receptor-bound conformation of the ligands, based on structure-activity profiles and conformational studies of the ligands. Small cyclic peptides, adopting a restricted number of conformations that can be theoretically predicted or experimentally determined, are particularly useful for this purpose. The second approach focuses on the receptor, employing site-directed mutagenesis and molecular modeling to deduce receptor structure. Our previous work combining these two approaches has led to the development of ligand-receptor interaction models for two closely related peptide series, analogs of cyclic tetrapeptides JOM-13 and JOM-6 (Fig. 1), selective for $\delta$ - and $\mu$-opioid receptors, respectively $(8,9)$.

Our efforts, so far, have been focused on the development of bioactive conformation of $\mu$ - and $\delta$-opioid ligands, determination of structural requirements for $\mathrm{Tyr}^{1}$ and $\mathrm{Phe}^{3}$ residues, which are regarded as key residues for recognition of cyclic tetrapeptides by $\mu$ - and $\delta$-opioid receptors (10-16), and the study of the role of residues from the binding pockets of the corresponding receptors $(9,17)$. We have determined that cyclization of tetrapeptides through an ethylene bridge, amidation of the $\mathrm{C}$-terminus, and restriction of the $\mathrm{Phe}^{3}$ side chain in the trans $\left(\chi^{1}=\sim 180^{\circ}\right)$ conformation favors $\mu$-receptor recognition, while cyclization through a disulfide bridge, a free carboxylate at the C-terminus, and restriction of the $\mathrm{Phe}^{3}$ side chain in the gauche $\left(\chi^{1}=\sim-60^{\circ}\right)$ conformation provides $\delta$-selectivity. Moreover, $\mu$-receptor mutagenesis and molecular modeling studies revealed that $\operatorname{Tyr}^{1}\left(\chi^{1}=\sim 180^{\circ}\right)$ of the $\mu$-selective agonist JOM-6 interacts with Asp $^{147}$ in transmembrane helix $3\left(\mathrm{TM}_{3}\right), \mathrm{His}^{297}$ in TM6, and a set of aromatic and aliphatic side chains from $\mathrm{TM}_{3}, \mathrm{TM}_{5}$, and TM6. Also, the Cterminal amide is close to $\mathrm{Glu}^{229}$ in $\mathrm{TM}_{5}$, while $\mathrm{Phe}^{3}\left(\chi^{1}=\right.$ $\sim 180^{\circ}$ ) is located in a small cleft between extracellular loop 2 (EL2) and $\mathrm{TM}_{7}$ of the $\mu$-receptor, where $\operatorname{Trp}^{318}$ (from TM7), corresponding to $\mathrm{Leu}^{300}$ in the $\delta$-receptor or $\mathrm{Tyr}^{312}$ in the $\kappa$ receptor, is largely responsible for selective interaction with the $\mathrm{Phe}^{3}$ aromatic ring of JOM- 6 and its analogs (9).

The current study of analogs of these cyclic tetrapeptides extends this approach toward the elucidation of the ligand pharmacophore for the $\kappa$-opioid receptor. The pharmacologic studies reveal that while the binding profiles of the $\mu$ - and $\delta$-receptor are relatively similar, the profile of the $\kappa$-receptor is unique. As a means of uncovering the molecular mechanisms of $\kappa$-specificity we focused our attention on substitutions of the $\mathrm{Phe}^{3}$ residue of cyclic tetrapeptides. The Phe residue in the 'opioid core' sequence Tyr- $(\mathrm{Gly})_{n}$-Phe $(n=1,2)$ is considered a part of an 'address', which contributes to ligand selectivity (18). The work presented here explores analogs of JOM-6 and JOM-13 that probe the steric, lipophilic, and electronic requirements of residue 3 as an approach to improve affinity of peptides toward $\kappa$-receptors. Moreover, modification of D-Pen ${ }^{4}$ to the
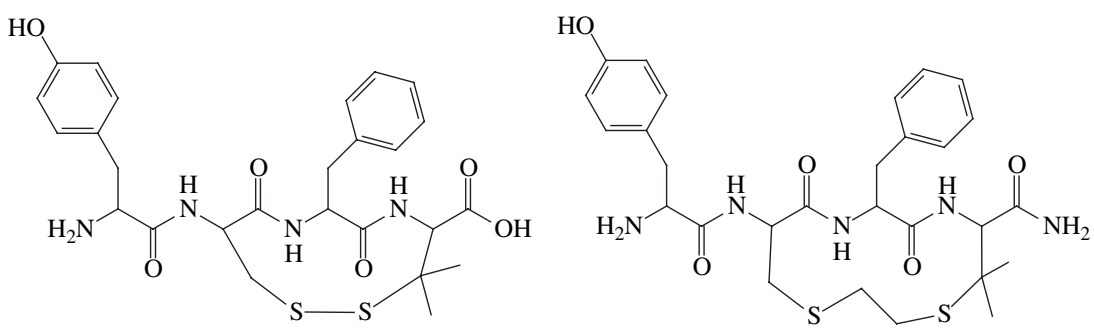

Figure 1. Structures of JOM-13 and JOM-6. 
less conformationally restricted D-Cys residue, designed to facilitate the adjustment of the conformation of the tetrapeptide cycle to the $\kappa$-receptor binding pocket, is also described. Molecular modeling of the active conformation of the $\kappa$-receptor in complex with designed tetrapeptides helps to explain the improved affinity toward $\kappa$-receptors of D-Cys ${ }^{4}$-containing cyclic tetrapeptides with aromatic residues in the third position.

\section{Results and Discussion}

\section{Roles of residues 3 and 4 in cyclic tetrapeptide ligand recognition by к-receptor}

As shown in Table 1, the previously developed $\mu$ - and $\delta$-selective cyclic tetrapeptides JOM-6 and JOM-13, as well as the related $\mu$ - and $\delta$-active analog, JOM-5, display only micromolar binding affinity to $\kappa$-opioid receptors. In an attempt to improve $\kappa$-receptor recognition, we examined different types of side chain replacement (aliphatic, basic, and aromatic side chains) for the important third residue (Phe in JOM-5, JOM-6, and JOM-13) and tested these peptides for binding affinity to $\mu-, \delta$ - and $\kappa$-opioid receptors stably expressed in mammalian cells (Table 1). As in JOM-5, JOM-6, and JOM-13, all new analogs were conformationally constrained via cyclization through residues 2 and 4 , as disulfides or ethylene dithioethers.

In the first series of peptides (1-8) we incorporated aliphatic side chains of different size (Gly, Ala, Aib, Cha) as $\mathrm{Phe}^{3}$ replacements and tested these compounds for opioid receptor binding affinity (Table 1). Of these analogs, only $\mathrm{Cha}^{3}$ replacement (compounds 7 and 8), was well-tolerated by $\mu$ - and $\delta$-receptors $\left(\mathrm{Ki}^{\mu}=1.1 \mathrm{nM}, \mathrm{Ki}^{\delta}=11.5 \mathrm{nM}\right.$, and $\mathrm{Ki}^{\mu}=15.1 \mathrm{nM}, \mathrm{Ki}^{\delta}=11.8 \mathrm{nM}$ for 7 and 8 , respectively). However, none of the analogs in this series displayed significant binding to the $\kappa$-receptor.

Next, we explored the effect of basic residue substitutions (Lys, Arg, homo-Arg) for Phe ${ }^{3}$ in JOM-5 and JOM-6 analogs. Compounds 9-14 were designed to take advantage of possible electrostatic interaction between basic amine or guanidinium groups of ligand side chains and numerous acidic residues in $\mathrm{EL}_{2}$ and $\mathrm{EL}_{3}$ of the $\kappa$-receptor that might be involved in peptide binding, judging from $\kappa$-receptor mutagenesis and opioid receptor chimera studies $(19,20)$. We observed that all these substitutions resulted in severe loss of binding to all opioid receptor types. Only the $\mathrm{Arg}^{3}$ and homo-Arg ${ }^{3}$ analogs (11-14) displayed significant $(\sim 1 \mu \mathrm{M})$ binding affinity and this was limited to only $\mu$-re- ceptors. In all other cases, the $\mu$-, $\delta$ - and $\kappa$-affinities were very weak $(\mathrm{Ki}>10$ o0o $\mathrm{nM})$.

Compounds 15 and 16, in which D-Pen ${ }^{4}$ is replaced by D-Cys ${ }^{4}$, while $\mathrm{Phe}^{3}$ is retained, were prepared to examine whether conformational restrictions imposed by the $\beta$, $\beta$-dimethyl substituents of D-Pen might be hindering interactions with the $\kappa$-receptor. Such substitution could also affect the distribution between low energy conformations of the peptide cycle. As seen in Table 1, the incorporation of D-Cys ${ }^{4}$ into compound $\mathbf{1 5}$, with cyclization via an ethylene dithioether bridge, yielded little improvement of $\kappa$-binding affinity $\left(\mathrm{Ki}^{\kappa}=1320 \mathrm{nM}\right)$, when compared with the parent peptide, JOM-6 $\left(\mathrm{Ki}^{\kappa}=2650 \mathrm{nM}\right)$. However, the presence of D-Cys ${ }^{4}$ combined with cyclization through a disulfide bridge dramatically increased $\kappa$-affinity ( 70-fold) relative to its parent peptide, JOM-5. The resulting peptide, 16, displayed moderate-to-high binding affinity to all three opioid receptors $\left(\mathrm{Ki}^{\mu}=1.26 \mathrm{nM}, \mathrm{Ki}^{\delta}=16.1 \mathrm{nM}\right.$, $\left.\mathrm{Ki}^{\kappa}=38.7 \mathrm{nM}\right)$.

In an attempt to further improve $\kappa$-affinity, we examined $\mathrm{Phe}^{3}$ replacements using aromatic side chains with variable lipophilicity, size, electronic properties and orientation of aromatic ring. Thus, tetrapeptides 17-24, derivatives of peptides 15 and 16 with $\mathrm{Tyr}^{3}{ }_{-}, p-\mathrm{NH}_{2} \mathrm{Phe}^{3}{ }_{-}$, or $\mathrm{Trp}^{3}{ }^{3}$-substitutions for $\mathrm{Phe}^{3}$, were synthesized and evaluated for opioid receptor affinity (Table 1). In these analogs, D-Cys ${ }^{4}$, which apparently favors $\kappa$-receptor recognition, was retained.

As seen in Table 1, the results of $\mathrm{Phe}^{3}$ replacement were dependent on the mode of peptide cyclization. In general, cyclization via a dithioether bridge resulted in reduced $\kappa$-binding relative to the corresponding disulfide ( 15 vs. 16; 17 vs. $18 ; 19$ vs. 20 ). Trp ${ }^{3}$-substitution is a notable exception as dithioether-containing $\mathbf{2 3}$ has only twofold lower $\kappa$-affinity than disulfide containing $\mathbf{2 4}$. Less can be said about $p-\mathrm{NH}_{2} \mathrm{Phe}^{3}$-substitution, as both dithioether- and disulfide-containing analogs (21 and 22) show no appreciable binding to the $\kappa$-receptor. Compared with the $\mathrm{Phe}^{3}$ containing lead peptide 16, substitution by bulkier (Trp, $p$ - $\left.\mathrm{NH}_{2} \mathrm{Phe}\right)$, more polar, $\mathrm{H}$-bond capable (Tyr, $p$ - $\left.\mathrm{NH}_{2} \mathrm{Phe}\right)$, or stereochemically altered $\left(\mathrm{D}-\mathrm{Phe}^{3}\right)$ residues all result in losses of $\kappa$-binding affinity.

Comparison of binding affinity data for the tested compounds (Table 1) allows several conclusions about structural requirements for cyclic tetrapeptides binding to different opioid receptors (Table 2). An aromatic residue in the third position of the tetrapeptides appears to be essential for $\kappa$-receptor recognition and favorable for binding to $\mu$ - and $\delta$-receptors. The presence of $\mathrm{Cha}^{3}$ is well-tolerated 
Table 1. Opioid receptor-binding affinity for standard peptides (E2078, JOM-6, JOM-5, JOM-13) and new cyclic tetrapeptide analogs with Phe ${ }^{3}$ - substitution

\begin{tabular}{|c|c|c|c|c|c|}
\hline \multirow[b]{2}{*}{ Peptide sequence } & \multirow[b]{2}{*}{ Bridge $^{a}$} & \multirow[b]{2}{*}{ Analog } & \multicolumn{3}{|c|}{$K_{i}(n M) \pm S E M$} \\
\hline & & & $\mu$ & $\delta$ & $\kappa$ \\
\hline$\left[N\right.$-Met-Tyr ${ }^{1}, N$-Met-Arg ${ }^{7}$-D-Leu ${ }^{8}$ ]-DynA(1-8)-EtNH 2 & - & E2078 & $0.1 \pm 0.01$ & $1.5 \pm 0.06$ & $0.67 \pm 0.08$ \\
\hline Tyr-c[D-Cys-Phe-D-Pen]-NH ${ }_{2}$ & S-Et-S & JOM-6 & $0.17 \pm 0.02$ & $12.0 \pm 1.40$ & $2650 \pm 401$ \\
\hline Tyr-c[D-Cys-Phe-d-Pen]-NH ${ }_{2}$ & S-S & JOM-5 & $5.2 \pm 2.6$ & $5.4 \pm 0.78$ & $2990 \pm 1500$ \\
\hline Tyr-c[D-Cys-Phe-D-Pen]-OH & S-S & JOM-13 & $197 \pm 53$ & $1.3 \pm 0.06$ & $>10000$ \\
\hline Tyr-c[D-Cys-Aib-D-Pen]-NH 2 & S-Et-S & 1 & $286 \pm 73$ & $941 \pm 52.8$ & $>10000$ \\
\hline Tyr-c[D-Cys-Aib-D-Pen]-NH ${ }_{2}$ & S-S & 2 & $>10000$ & $3880 \pm 148$ & $>10000$ \\
\hline Tyr-c[D-Cys-Ala-D-Pen]-NH ${ }_{2}$ & S-Et-S & 3 & $507 \pm 86.7$ & $1360 \pm 7.7$ & $>10000$ \\
\hline Tyr-c[D-Cys-Ala-D-Pen]-NH ${ }_{2}$ & S-S & 4 & $>10000$ & $3410 \pm 332$ & $>10000$ \\
\hline Tyr-c[D-Cys-Gly-D-Pen]-NH & S-Et-S & 5 & $473 \pm 29.4$ & $1270 \pm 179$ & $>10000$ \\
\hline Tyr-c[D-Cys-Gly-D-Pen]-NH ${ }_{2}$ & S-S & 6 & $1160 \pm 158$ & $682 \pm 85$ & $>10000$ \\
\hline Tyr-c[D-Cys-Cha-d-Pen]-NH ${ }_{2}$ & S-Et-S & 7 & $1.1 \pm 0.15$ & $11.5 \pm 2.54$ & $>10000$ \\
\hline Tyr-c[D-Cys-Cha-d-Pen]-NH ${ }_{2}$ & S-S & 8 & $15.1 \pm 2.48$ & $11.8 \pm 2.05$ & $>10000$ \\
\hline Tyr-c[D-Cys-Lys-D-Pen]-NH ${ }_{2}$ & S-Et-S & 9 & $>10000$ & $>10000$ & $>10000$ \\
\hline Tyr-C[D-Cys-Lys-D-Pen]-NH ${ }_{2}$ & S-S & 10 & $>10000$ & $>10000$ & $>10000$ \\
\hline Tyr-c[D-Cys-Arg-D-Pen]-NH ${ }_{2}$ & S-Et-S & 11 & $>10000$ & $594 \pm 46.5$ & $>10000$ \\
\hline Tyr-c[D-Cys-Arg-D-Pen]-NH ${ }_{2}$ & S-S & 12 & $>10000$ & $1440 \pm 63.6$ & $>10000$ \\
\hline Tyr-c[D-Cys-hArg-D-Pen]-NH & S-Et-S & 13 & $>10000$ & $586 \pm 21.3$ & $>10000$ \\
\hline Tyr-c[D-Cys-hArg-D-Pen]-NH & S-S & 14 & $>10000$ & $2120 \pm 58$ & $>10000$ \\
\hline Tyr-c[D-Cys-Phe-D-Cys]-NH ${ }_{2}$ & S-Et-S & 15 & $0.91 \pm 0.25$ & $50.0 \pm 22.4$ & $1320 \pm 196$ \\
\hline Tyr-c[D-Cys-Phe-D-Cys]-NH ${ }_{2}$ & S-S & 16 & $1.26 \pm 0.25$ & $16.1 \pm 3.77$ & $38.7 \pm 1.84$ \\
\hline Tyr-C[D-Cys-D-Phe-D-Cys]- $\mathrm{NH}_{2}$ & S-Et S & 17 & $1200 \pm 441$ & $2640 \pm 242$ & $>10000$ \\
\hline Tyr-C[D-Cys-D-Phe-D-Cys]-NH ${ }_{2}$ & S-S & 18 & $51.9 \pm 15.3$ & $179 \pm 24$ & $3010 \pm 283$ \\
\hline Tyr-C[D-Cys-Tyr-D-Cys]-NH ${ }_{2}$ & S-Et-S & 19 & ND & ND & $>10000$ \\
\hline Tyr-C[D-Cys-Tyr-D-Cys]-NH ${ }_{2}$ & S-S & 20 & $330 \pm 117$ & $21 \pm 1.8$ & $627 \pm 42$ \\
\hline Tyr-c[D-Cys- $p-\mathrm{NH}_{2}$ Phe-D-Cys]- $\mathrm{NH}_{2}$ & S-Et-S & 21 & $2.6 \pm 0.5$ & $655 \pm 44$ & $>10000$ \\
\hline Tyr-c[D-Cys- $p-\mathrm{NH}_{2}$ Phe-D-Cys]-NH ${ }_{2}$ & S-S & 22 & $160 \pm 18$ & $609 \pm 61$ & $>10000$ \\
\hline Tyr-c[D-Cys-Trp-D-Cys]-NH & S-Et-S & 23 & $34.9 \pm 4.0$ & $0.51 \pm 0.14$ & $370 \pm 75$ \\
\hline Tyr-c[D-Cys-Trp-D-Cys]-NH ${ }_{2}$ & S-S & 24 & $20.6 \pm 12.4$ & $1.3 \pm 0.3$ & $174 \pm 53$ \\
\hline
\end{tabular}

Table 2. The structural requirement for cyclic tetrapeptides with high affinity to $\mu$-, $\delta$ - and $\kappa$-receptors

\begin{tabular}{|c|c|c|c|c|c|c|c|c|}
\hline \multirow[b]{2}{*}{ Receptor (ligand) } & \multirow[b]{2}{*}{$\mathrm{Ki} \pm \mathrm{SEM}(\mathrm{nM})$} & \multirow[b]{2}{*}{ Residue 3} & \multirow[b]{2}{*}{ Residue 4} & \multirow[b]{2}{*}{ C-terminus } & \multirow[b]{2}{*}{ Bridge } & \multicolumn{3}{|c|}{ Side chain rotamer $\left(\sim \chi^{1},{ }^{\circ}\right)$} \\
\hline & & & & & & Residue $3^{a}$ & Residue $2^{\mathrm{b}}$ & Residue $4^{\mathrm{b}}$ \\
\hline$\mu(J O M-6)$ & $0.17 \pm 0.02$ & $\mathrm{Phe}^{3}$ & D-Pen ${ }^{4}$ & $\mathrm{CONH}_{2}$ & S-Et-S & 180 & 180 & -60 \\
\hline$\delta(J O M-13)$ & $1.3 \pm 0.06$ & $\mathrm{Phe}^{3}$ & D-Pen ${ }^{4}$ & $\mathrm{COO}^{-}$ & S-S & -60 & 180 & -60 \\
\hline$\kappa(16)$ & $38.7 \pm 1.84$ & $\mathrm{Phe}^{3}$ & D-Cys ${ }^{4}$ & $\mathrm{CONH}_{2}$ & S-S & 180 & -60 & 60 \\
\hline
\end{tabular}


in $\mu$ - and $\delta$-receptors, but is unfavorable for binding to $\kappa$-receptors. Cyclization via an ethylene dithioether bridge favors $\mu$-receptor binding, while the smaller disulfide-containing cycle is preferred for peptide recognition by $\delta$ - and $\kappa$-receptors. The presence of a C-terminal amide favors ligand binding to $\mu$ - and $\kappa$-receptors, while a free C-terminal carboxylate favors binding to the $\delta$-receptor and enhances $\delta$-receptor selectivity by diminishing binding to $\mu$ - and $\kappa$-receptors. The presence of $\mathrm{D}$-Cys ${ }^{4}$ in place of D-Pen ${ }^{4}$ in the tripeptide cycle dramatically increases $\kappa$-binding affinity of the tetrapeptides, while retaining high $\mu$ - and $\delta$-affinity. To reveal the molecular mechanisms underlying differences in structural requirements for recognition of tetrapeptides from this series by the three opioid receptors we modeled the active $\kappa$-receptor in complex with cyclic tetrapeptides and compared the result with our previously developed model of the active $\mu$-receptor in complex with JOM-6 (9).

\section{Homology model of active $\kappa-$-opioid receptor with bound cyclic tetrapeptide}

Homology modeling of the $\kappa$-receptor in complex with cyclic tetrapeptides (JOM-6 and peptide 16) was undergone using distance geometry methods, as described in Experimental Procedures. The sequence alignment of opioid receptors and rhodopsin was previously verified using intrinsic and engineered $\mathrm{Zn}^{2+}$-binding centers and many other experimental data (17). The alignment assumes disappearance of an $\alpha$-aneurism in TM2 existing in rhodopsin and conservation of the $\beta$-hairpin observed in EL2 of rhodopsin. This $\beta$-hairpin, connected by a conserved disulfide bridge to $\mathrm{TM}_{3}$, is a typical feature of many rhodopsin-like GPCRs $(6,7,17,21-24)$ and can be expected to occur in opioid receptors based upon their sequence similarity to rhodopsin in this region $(17)$.

The $\kappa$-receptor model calculated here is a significant improvement over earlier models that were calculated with hydrogen bonding constraints (21), or obtained from the bacteriorhodopsin template and low-resolution electron microscopic (EM) maps (25-32). Moreover, it also differs from automated modeled $\kappa$-receptors deposited in MODBASE (33) in several important details, such as target-template sequence alignment in $\mathrm{TM}_{2}, \mathrm{TM}_{7}$, and $\mathrm{EL}_{2}$. The present $\kappa$-receptor model is close to the crystal structure of rhodopsin (7) with RMSD of $2.21 \AA$ for $212 \mathrm{C} \alpha$-atoms (TM domain) and $1.43 \AA$ for $174 \mathrm{C} \alpha$-atoms (all $\alpha$-helices, except TM6). It also reproduces TM6 movement, shift of EL2 and other characteristics of our structural template, the activated $\mu$-receptor (9), which was recently calculated from the crystal structure of rhodopsin and a set of 'activating' distance constraints, derived from experimental studies of different GPCRs in the active conformation (9). The tetrapeptide ligands (JOM-6 and peptide 16) were included in calculations of $\kappa$-receptors in a manner similar to the calculation of the $\mu$-receptor-JOM-6 complex (9).

The calculated model of the active $\kappa$-receptor with bound peptide $\mathbf{1 6}$ is nearly identical to the $\mu$-receptor model with JOM-6 in the TM domain (RMSD $0.76 \AA$ for 212 C $\alpha$-atoms). In the area of the $\mathrm{Tyr}^{1}$-binding site, the aromatic side chain of $\mathrm{Tyr}^{1}$ is surrounded by $\mathrm{Tyr}^{139}{ }^{139} \mathrm{Met}^{142}$, $\mathrm{Phe}^{143}$, and $\mathrm{Phe}^{231}$. $\mathrm{Tyr}^{1}$ has aromatic interactions with the indole ring of $\operatorname{Trp}^{287}$, its $\mathrm{N}^{+}$group forms an ionic pair with $\mathrm{Asp}^{138}$, and its $\mathrm{O}^{\eta} \mathrm{H}$ group forms $\mathrm{H}$-bonds with $\mathrm{His}^{291}$ and the backbone of $\mathrm{Ala}^{234}$ (Fig. 2). These interactions of the tyramine portion of the ligands are conserved for all opioid receptors $(17,21)$.

However, another area of the binding pocket, responsible for interactions with the third and fourth residues of the tetrapeptides, differs among the three opioid receptors. The key residues that appear to be responsible for selective interaction of peptide ligands with these receptors are located in TM6 $\left(\mathrm{Lys}^{303}\right.$ in $\mu$-, $\mathrm{Trp}^{294}$ in $\delta$ - and $\mathrm{Glu}^{297}$ in $\kappa$-receptor), $\mathrm{TM}_{7}\left(\operatorname{Trp}^{318}\right.$ in $\mu$-, $\mathrm{Leu}^{300}$ in $\delta$ - and $\mathrm{Tyr}^{312}$ in $\kappa$-receptor), and EL2 (17). In the $\mu$-receptor, the $\mathrm{Phe}^{3}$ side chain of JOM-6 $\left(\chi^{1}=\sim 180^{\circ}\right)$ occupies a cleft between EL2and $\mathrm{TM}_{7}$, and has effective aromatic interactions with $\operatorname{Trp}^{318}$ from TM7 and $\mathrm{Phe}^{221}$ from EL2 (Fig. 3A). This cleft provides enough space for $\mathrm{Phe}^{3}$. Further, the peptide D-Pen ${ }^{4}$ residue interacts with $\mathrm{Lys}^{303}$ from TM6 and the C-terminal $\mathrm{CONH}_{2}$ is pointed between $\mathrm{TM}_{5}\left(\mathrm{Glu}^{229}\right)$ and
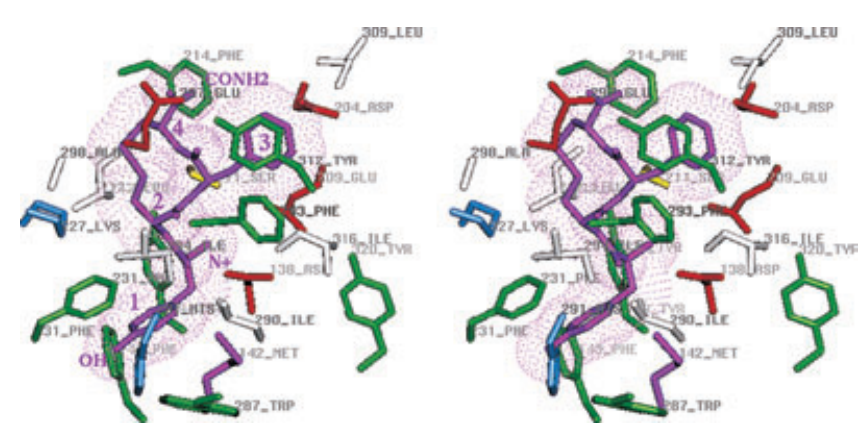

Figure 2. Stereoview of peptide $\mathbf{1 6}$ (Tyr-c[D-Cys-Phe-D-Cys] $\mathrm{NH}_{2}$, S-S bridge) inside the $\kappa$-opioid receptor binding pocket. Ligand is represented in purple 'licorice' surrounded by dot surface. Receptor residues participating in the interaction with $\mathrm{Tyr}^{1}$ and $\mathrm{Phe}^{3}$ are shown colored by residue type: white for aliphatic, green for aromatic, yellow for uncharged polar, red for acidic, blue for basic, purple for sulfur-containing residues. 

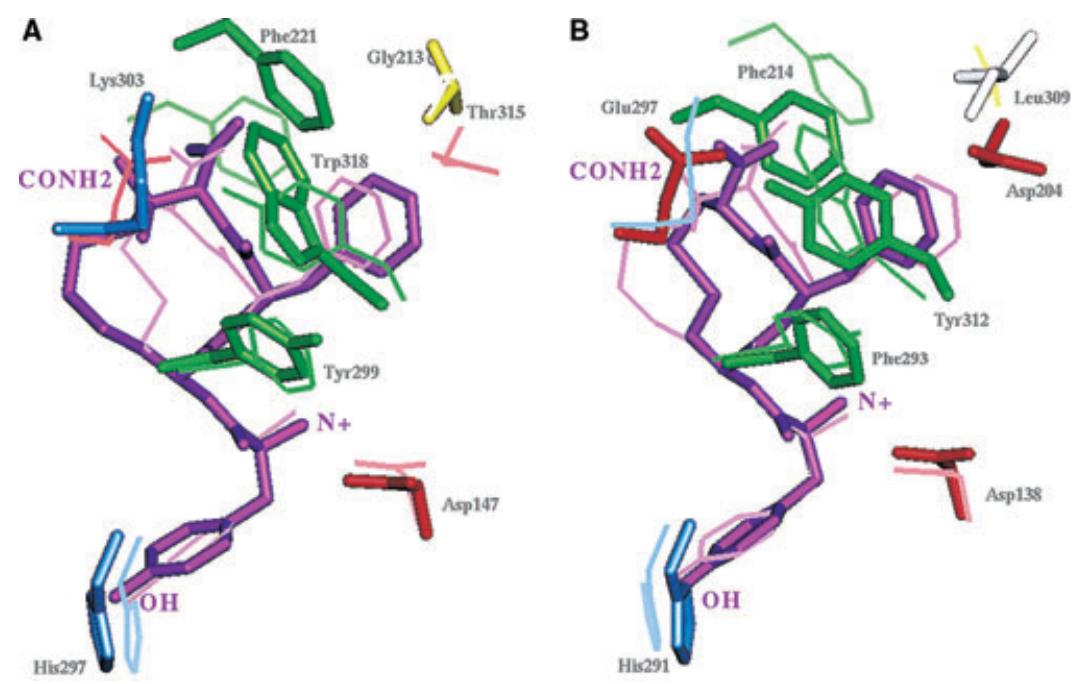

Figure 3. JOM-6 in the $\mu$-opioid receptor binding pocket (A, thick lines) and peptide $\mathbf{1 6}$ in the $\kappa$-opioid receptor binding pocket (B, thick lines). In each figure, ligand and receptor residues from the other figure are depicted in thin lines for comparison. Ligands are colored purple, receptor residues are colored by residue type, as in Fig. 2.

EL2 $\left(\mathrm{Phe}^{221}\right)$. At the $\delta$-receptor the peptide ligand's $\mathrm{Phe}^{3}$ side chain $\left(\chi^{1}=\sim-60^{\circ}\right)$ is also located in a cleft between $\mathrm{EL}_{2}$ and $\mathrm{TM}_{7}$, interacting with $\mathrm{Leu}^{300}$ from $\mathrm{TM}_{7}$ and $\mathrm{Phe}^{202}$ from EL2, while D-Pen ${ }^{4}$ contacts with $\mathrm{Trp}^{284}$ from TM6 and the C-terminal -COO- is located between EL2 and TM5.

In contrast, in the $\kappa$-opioid receptor, the cleft between $\mathrm{TM}_{7}$ and EL2 is narrowed because of two residues inserted into the $\beta$-turn of the $\beta$-hairpin in $\mathrm{EL}_{2}, \mathrm{Asp}^{204}$, and $\mathrm{Val}^{205}$. The corresponding residues are present in bovine rhodopsin but are missing in $\mu$ - and $\delta$-opioid receptors. For cyclic tetrapeptide ligands the side chain of $\mathrm{Phe}^{3}$, but not the larger $\operatorname{Trp}^{3}$ side chain, can squeeze into the tight cleft between $\mathrm{TM}_{7}$ and $\mathrm{EL}_{2}$, interacting with $\mathrm{Tyr}^{312}$ (substituted for $\operatorname{Trp}^{318}$ of the $\mu$-receptor), $\mathrm{Phe}^{214}$ and polar side chains of $\mathrm{Asp}^{204}$ and $\mathrm{Glu}^{209}$ from EL2 (Fig. $3 \mathrm{~B}$ ). The Trp $\rightarrow$ Tyr replacement in $\mathrm{TM}_{7}$ of the $\kappa$-receptor and the smaller-size of the binding cleft may contribute to the 30 -fold decreased binding affinity of peptide $\mathbf{1 6}$ for the $\kappa$-receptor, relative to the $\mu$-receptor.

The most intriguing result in Table 1 is the dramatic improvement of $\kappa$-recognition by peptide $\mathbf{1 6}$ (with D-Cys ${ }^{4}$ and S-S bridge) relative to JOM-5 (with D-Pen ${ }^{4}$ and S-S bridge), to peptide $\mathbf{1 5}$ (with D-Cys ${ }^{4}$ and dithioether bridge), or to JOM-6 (with D-Pen ${ }^{4}$ and dithioether bridge). The comparison of modeled complexes of $\mu$-receptor with bound JOM-6 and of $\kappa$-receptor with bound peptide $\mathbf{1 6}$ helps explain these results. In the $\kappa$-receptor, the space available for interaction with the ligand's fourth residue and disulfide/dithioether bridge is reduced relative to the $\mu$-binding pocket because of the insertion of one residue in EL2 near $\mathrm{TM}_{5}$. As a result, the narrowed binding pocket of the $\kappa$-receptor can more easily accommodate peptides with a smaller-size cycle. This explains the better $\kappa$-binding affinity of peptides with a disulfide bridge and D-Cys ${ }^{4}$ relative to peptides with dithioether bridge and $\mathrm{D}-\mathrm{Pen}^{4}$. Moreover, in the tight $\kappa$-receptor pocket, peptide 16, with a tripeptide cycle conformation analogous to JOM-6 at the $\mu$-receptor (9), displays hindrances between its C-terminal carboxamide and $\mathrm{Phe}^{214}$ in EL2. The $\mu$-receptor bound conformation of JOM-6 represents the lowest energy conformation of the peptide cycle with $\chi^{1}=\sim 180^{\circ}$ for D-Cys ${ }^{2}$ and $\chi^{1}=\sim-60^{\circ}$ for D-Pen ${ }^{4}(9)$. A similar conformation of the disulfide bridge was deduced for the $\delta$-receptor-bound conformation of JOM-13 and JOM-5 (14). However, only a higher energy, alternative conformation of the disulfide bridge in peptide $16\left(\chi^{1}=\sim-60^{\circ}\right.$ for D-Cys ${ }^{2}$ and $\chi^{1}=\sim 60^{\circ}$ for D-Pen ${ }^{4}$, which reorients the carboxamide toward TM6, can fit the smaller $\kappa$-binding pocket. For the D-Pen ${ }^{4}$-containing JOM-5, the energy gap between the proposed $\delta$-receptor bound conformation and the alternative conformation is $>3.5 \mathrm{kcal} / \mathrm{mol}$, but this gap decreases to $\sim 2 \mathrm{kcal} /$ $\mathrm{mol}$ in $\mathrm{D}$-Cys ${ }^{4}$-containing peptide 16. As a result, the energy penalty for binding in an unfavorable cycle conformation is much smaller for D-Cys ${ }^{4}$-containing peptides and explains their reasonably high $\kappa$-affinity. At the same time, this $\sim 2 \mathrm{kcal} / \mathrm{mol}$ energy penalty correlates well with the $\sim 30$-fold higher affinity of $\mathbf{1 6}$ for the $\mu$ - vs. $\kappa$-receptor, as for binding of $\mathbf{1 6}$ to the $\mu$-receptor the lowest energy conformation is allowed. 


\section{Conclusions}

Our receptor modeling exposes differences between the ligand-binding pockets of $\mu$-, $\delta$-, and $\kappa$-opioid receptors in the area of the likely interaction site with the third and the fourth residues of the ligands. We have recently shown that, in $\mu$ and $\delta$-receptors, $\mathrm{EL}_{3}$ and the extracellular parts of $\mathrm{TM}_{6}, \mathrm{TM}_{7}$ are important for binding of cyclic tetrapeptides $(8,9,17)$. In particular, $\mathrm{Phe}^{3}$ of the tetrapeptide interacts with a cleft between $\mathrm{EL}_{2}$ and $\mathrm{TM}_{7}$, where $\operatorname{Trp}^{318}$ from TM7 of $\mu$-receptors or the corresponding Leu ${ }^{300}$ of $\delta$-receptors is implicated in selective recognition of $\mathrm{Phe}^{3}$ in trans- or gauche-orientations, respectively. Moreover, Lys $^{303}$ from TM6 of the $\mu$ receptor or the corresponding $\operatorname{Trp}^{284}$ of the $\delta$-receptor forms additional specific interactions with D-Pen ${ }^{4}$ of tetrapeptides.

Our current $\kappa$-receptor model demonstrates that, in the $\kappa$-receptor, the binding pocket between EL2, TM6, and TM7 is narrowed due to insertion of two residues in the $\beta$-turn of $\mathrm{EL}_{2}$ and one residue in EL2 near TM5. The tight cleft between $\mathrm{TM}_{7}$ and $\mathrm{EL}_{2}$ can only accept the small aromatic side chain of $\mathrm{Phe}^{3}$ while the larger $\mathrm{Tyr}^{3}, p-\mathrm{NH}_{2} \mathrm{Phe}^{3}$, and $\operatorname{Trp}^{3}$ side chains are not accommodated. Accordingly, the $\mathrm{Phe}^{3}$, D-Cys ${ }^{4}$-containing peptide, 16, displayed the best $\kappa$-binding affinity of the series $(\mathrm{Ki}=38.7 \mathrm{nM})$. In the $\kappa$-receptor, Phe ${ }^{3}$ of $\mathbf{1 6}$ effectively interacts with $\mathrm{Tyr}^{312}$ from $\mathrm{TM}_{7}$, $\mathrm{Phe}^{214}$, and $\mathrm{Asp}^{204}$ from EL2. The lower $\kappa$-binding affinity of this peptide relative to its $\mu$-receptor binding is consistent with the steric constraint imposed by EL2 of the $\kappa$-receptor, which requires 16 to assume a high-energy conformation of its peptide cycle in the tight $\kappa$-binding pocket.

As noted above, the tetrapeptide residue 3-binding site of the $\kappa$-receptor includes the polar, acidic side chains of Asp $^{204}$ from EL2 and Glu ${ }^{297}$ from TM6. Attempts to exploit these acidic residues for improved binding by incorporating $\mathrm{Lys}^{3}, \mathrm{Arg}^{3}$, or hArg ${ }^{3}$ in tetrapeptides were unsuccessful presumably due to the water-exposed nature of this binding region, such that any energy gain from electrostatic interactions between the basic peptide side chain and the acidic receptor residues is offset by the energy cost of dehydration of these polar residues.

\section{Experimental Procedures}

\section{Materials}

All Fmoc-protected amino acids were obtained from Advanced ChemTech (Louisville, KY, USA) or Chem-
Impex International (Wood Dale, IL, USA). All other reagents were from Sigma-Aldrich (St. Louis, MO, USA) unless otherwise indicated.

\section{Solid-phase peptide synthesis}

All peptides were synthesized by solid-phase methods on an ABI Model 431A solid-phase peptide synthesizer (Applied Biosystems, Foster City, CA, USA). Rink resin (Advanced ChemTech, Louisville, KY, USA) was used as the solid support for C-terminal carboxamide peptides. Peptide elongation on the peptide-resin involved treating resin with piperidine (Aldrich, Milwaukee, WI, USA) to cleave the Fmoc-protecting group, followed by coupling of the next amino acid with o-benzotriazol-1-yl- $N, N, N^{\prime}, N^{\prime}$-tetramethyl uronium hexafluorophosphate (HBTU) and 1-hydroxybenzotriazole (HOBt) (Applied Biosystems). Trifluoroacetic acid $/ \mathrm{H}_{2} \mathrm{O} /$ thioanisole/ethylenedithiol $(9: 0.5: 0.25: 0.25$, $\mathrm{v} / \mathrm{v} / \mathrm{v} / \mathrm{v}$ ) was used to cleave the linear peptide from the resin and simultaneously remove the side chain-protecting groups. The peptide solution was filtered from the resin and then subjected to preparative reverse-phase high-performance liquid chromatography (RP-HPLC) to afford the linear disulfhydryl-containing peptide. Final product confirmation was obtained by ESI-LC-MS (ThermoFinnigan, San Jose, CA, USA).

\section{General method for disulfide cyclization of peptides}

To obtain disulfide cyclized peptide, linear disulfhydrylcontaining peptide was dissolved in a $1 \%(\mathrm{v} / \mathrm{v})$ acetic acid (HOAc) in $\mathrm{H}_{2} \mathrm{O}$ solution (saturated with $\left.\mathrm{N}_{2}\right)$ at $5{ }^{\circ} \mathrm{C}(1 \mathrm{mg}$ linear peptide/mL of aqueous HOAc solution). The $\mathrm{pH}$ of the peptide solution was raised to 8.5 using $\mathrm{NH}_{4} \mathrm{OH}$, followed by the addition of $4 \mathrm{LEq}$ of $\mathrm{K}_{3} \mathrm{Fe}(\mathrm{CN})_{6}$. The reaction mixture was stirred for $1 \mathrm{~min}$, then quenched by adjusting the $\mathrm{pH}$ to 3.5 with HOAc. The mixture was then subjected to preparative RP-HPLC to afford the disulfide-cyclized peptide.

\section{General method for dithioether cyclization of peptides}

To form dithioether-containing cyclic peptides, linear disulfhydryl peptide was added to dimethylformamide and maintained at $5{ }^{\circ} \mathrm{C}$ under a $\mathrm{N}_{2}$ atmosphere $(0.1 \mathrm{mg}$ linear peptide/mL dimethylformamide). About $10 \mathrm{mEq}$ of potassium 
tert-butoxide were added to the peptide solution, followed by the addition of $10 \mathrm{mEq}$ of $\mathrm{Br}-\left(\mathrm{CH}_{2}\right)_{n}-\mathrm{Br}(n=1,2$, or 3). The reaction was quenched with $5 \mathrm{~mL}$ HOAc after $2 \mathrm{~h}$ and the solvent was removed in vacuo. The residue was dissolved in water, filtered, and then subjected to preparative RP-HPLC to afford the alkyl dithioether-cyclized peptide.

All final product peptides were $>95 \%$ pure as assessed by RP-HPLC on a Vydac 218TP C-1 8 column (The Nest Group, Southboro, MA, USA) using the solvent system $0.1 \%$ trifluoroacetic acid (TFA) in water/o.1\% TFA in acetonitrile by a gradient of $0-70 \%$ organic component in $70 \mathrm{~min}$, monitored at $230 \mathrm{~nm}$, and all peptides displayed the appropriate molecular weights as determined by mass spectrometry. Table 3 summarizes the analytical data for all 24 new peptides.

Table 3. Analytical data of peptides 1-24

\begin{tabular}{|c|c|c|c|}
\hline Analog & $\begin{array}{l}\text { Molecular } \\
\text { weight, } \\
\text { theoretical (MW) }\end{array}$ & $\begin{array}{l}\text { Molecular } \\
\text { weight } \\
\left(\mathrm{MW}+\mathrm{H}^{+}\right)^{\mathrm{a}}\end{array}$ & $\begin{array}{l}\operatorname{HPLC} \\
\left(\min ; R_{t}\right)^{b}\end{array}$ \\
\hline 1 & 525.2 & 526.2 & 21.4 \\
\hline 2 & 497.2 & 498.0 & 20.5 \\
\hline 3 & 511.2 & 512.2 & 19.8 \\
\hline 4 & 483.2 & 484.0 & 19.0 \\
\hline 5 & 497.2 & 498.1 & 19.6 \\
\hline 6 & 469.2 & 470.1 & 18.9 \\
\hline 7 & 593.3 & 594.2 & 28.5 \\
\hline 8 & 565.3 & 566.1 & 23.5 \\
\hline 9 & 568.3 & 569.2 & 19.8 \\
\hline 10 & 540.2 & 541.2 & 18.8 \\
\hline 11 & 596.3 & 597.4 & 19.8 \\
\hline 12 & 568.2 & 569.6 & 19.1 \\
\hline 13 & 610.3 & 611.4 & 19.9 \\
\hline 14 & 582.3 & 583.3 & 19.0 \\
\hline 15 & 559.2 & 560.2 & 20.9 \\
\hline 16 & 531.2 & 532.1 & 17.6 \\
\hline 17 & 559.2 & 560.2 & 20.6 \\
\hline 18 & 531.2 & 532.1 & 20.3 \\
\hline 19 & 547.2 & 548.1 & 15.3 \\
\hline 20 & 575.2 & 576.1 & 18.1 \\
\hline 21 & 602.3 & 603.2 & 19.8 \\
\hline 22 & 574.2 & 575.2 & 19.4 \\
\hline 23 & 598.2 & 599.1 & 22.9 \\
\hline 24 & 570.2 & 571.1 & 19.7 \\
\hline
\end{tabular}

a. Molecular weight determined by ESI-LC-MS.

b. Retention time assessed by analytical high-performance liquid chromatography (HPLC): $0-70 \%$ acetonitrile, $w / 0.1 \%$ trifluoroacetic acid (TFA) in $70 \mathrm{~min}, 230 \mathrm{~nm}$, samples in $\mathrm{H}_{2} \mathrm{O}$, $\mathrm{w} / 0.1 \%$ TFA (elution column heated at $35^{\circ} \mathrm{C}$ ).

\section{Radioligand-binding assays}

Opioid ligand-binding assays were based on the displacement by the test compounds of ${ }^{3} \mathrm{H}$-diprenorphine from opioid receptors (rat $\mu$ and $\delta$, human $\kappa$ ) cloned and stably expressed in rat glioma $\mathrm{C} 6$ cells $(\mu$ and $\delta$ ) or Chinese hamster ovary $(\kappa)$ cells as previously described $(34,35)$. The assay mixture, containing membrane suspension in $50 \mathrm{~mm}$ Tris buffer ( $\mathrm{pH}$ 7.4), radiolabeled ligand, and test compound, was incubated at $25^{\circ} \mathrm{C}$ in triplicate for $1 \mathrm{~h}$ to allow binding to reach equilibrium. Subsequently, the samples were filtered rapidly, and the radioactivity retained was determined by liquid scintillation counting. Inhibition of radiolabeled ligand binding by the test compounds was determined from maximal specific binding, measured with an appropriate excess of unlabeled naloxone $(10 \mu \mathrm{M})$. $\mathrm{IC}_{50}$-values were determined by nonlinear regression analysis to fit a logistic equation to the competition data and converted to Ki-values using GRAPHPAD PRISM software. The results presented are the mean \pm SEM from at least three separate assays.

\section{Distance geometry calculations of $\kappa$-receptor-tetrapeptide complexes}

The comparative modeling of human $\kappa$-receptor (residues 55-348, accession code P41145) was performed using the distance geometry program DIANA (36), QUANTA (Accelrys, San Diego, CA, USA), and our supplementary software, as described previously $(9,17,21,37)$. The $\mu$-opioid receptor model (active state) in complex with JOM-6 (9) was applied as a structural template. During distance geometry calculations, the spatial positions of all TM helices were restrained using the following upper distance constraints: (i) the corresponding $C^{\beta} \ldots C^{\beta}$ distances from the template, with deviations of $1 \AA$, (ii) a set of $\mathrm{H}$-bonds specific for $\kappa$ opioid receptor (O...O, N...O distances of $2.9 \AA$ ), and (iii) a conserved disulfide bond between $\mathrm{Cys}^{131}$ and $\mathrm{Cys}^{210}$ $\left(S^{\gamma} \ldots S^{\gamma}, C^{\beta} \ldots C^{\beta}, C^{\beta} \ldots S^{\gamma}\right.$ distances of $2.04,4.20,3.05 \AA$, respectively). This allowed small spatial adjustments of all $\alpha$-helices during the calculations. The dihedral angles of receptor residues were generally taken as in the template, with allowed deviations of $30^{\circ}$. The side chain rotamers of some residues nonidentical in $\mu$ - and $\kappa$-receptors were changed to remove steric clashes and to maximize the number of interhelical H-bonds. The standard target function weights and minimization protocol were applied (36). The pairwise RMSD between the 10 best calculated models of the $\kappa$-receptor was $<0.6 \AA$ (for $294 \mathrm{C}^{\alpha}$-atoms). 
Cyclic peptides were included in the distance geometry calculations as described previously (9). The lowest energy conformers of peptide $\mathbf{1 6}$ with relative energies $\Delta^{\mathrm{E}}<5 \mathrm{kcal} / \mathrm{mol}$ and four alternative conformations of disulfide bridge were obtained by molecular mechanics computations using the QUANTA2000.2/charms force field (14). These conformers were tested during modeling of $\kappa$-receptor-peptide complexes. Moreover, we concluded that the aromatic side chain of residue 3 of the peptide ligand would have a trans-rotamer when bound to the $\kappa$-receptor, similar to the orientation of $\mathrm{Phe}^{3}$ bound to the $\mu$, but not the $\delta$-receptor (8). This conclusion was based on our previous data, which indicated that the incorporation of $\Delta^{\mathrm{E}}-\mathrm{Phe}^{3}$ in JOM-5, which fixes the aromatic side chain in a transorientation, improves $\kappa$-affinity $(15,16)$.

Acknowledgements: The authors are grateful to Andrei Lomize for helpful discussions. These studies were supported by grant DA03910 from the National Institute on Drug Abuse (NIDA).

\section{References}

1. Mansour, A., Hoversten, M.T., Taylor, L.P., Watson, S.J. \& Akil, H. (1995) The cloned $\mathrm{mu}$, delta and kappa receptors and their endogenous ligands: evidence for two opioid peptide recognition cores. Brain Res. 700, 89-98.

2. Kieffer, B.L. (2000) Opioid receptors: from genes to mice. J. Pain 1(Suppl. 3), 45-50.

3. Watson, S. \& Arkinstall, S. (1994) The G-protein Linked Receptor Facts Book. pp. 1-294. Academic Press, San Diego, USA.

4. Flower, D.R. (1999) Modeling G-proteincoupled receptors for drug design. Biochim. Biophys. Acta 1422, 207-234.

5. Waldhoer, M., Bartlett, S.E. \& Whistler, J.L. (2004) Opioid receptors. Annu. Rev. Biochem. 73, 953-990.

6. Palczewski, K., Kumasaka, T., Hori, T., Behnke, C.A., Motoshima, H., Fox, B.A., Le Trong, I., Teller, D.C., Okada, T., Stenkamp, R.E., Yamamoto, M. \& Miyano, M. (2000) Crystal structure of rhodopsin: a G protein-coupled receptor. Science $\mathbf{2 8 9}$, 739-745.

7. Li, J., Edwards, P.C., Burghammer, M., Villa, C. \& Schertler, G.F. (2004) Structure of bovine rhodopsin in a trigonal crystal form. J. Mol. Biol. 343, 1409-1438.

8. Mosberg, H.I. \& Fowler, C.B. (2002) Development and validation of opioid ligand-receptor interaction models: the structural basis of mu vs. delta selectivity. J. Pept. Res. 6o, 329-335.

9. Fowler, C., Pogozheva, I.D., Lomize, A.L., LeVine, H. III \& Mosberg, H.I. (2004) Complex of and active $\mu$-opioid receptor with cyclic peptide agonist modeled from experimental constraints. Biochemistry 43, 15796-15810.

10. Mosberg, H.I., Omnaas, J.R., Medzihradsky, F. \& Smith, C.B. (1988) Cyclic, disulfide- and dithioether-containing opioid tetrapeptides: development of a ligand with high delta opioid receptor selectivity and affinity. Life Sci. 43, 1013-1020.
11. Mosberg, H.I., Lomize, A.L., Wang, C., Kroona, H., Heyl, D.L., Ma, W., Sobczyk-Kojiro, K., Mousigian, C. \& Porreca, F. (1994) Development of a model for the $\delta$-opioid receptor pharmacophore: 1 . Conformationally restricted $\mathrm{Tyr}^{1}$ replacements in the cyclic $\delta$ receptor selective tetrapeptide Tyr-c[D-Cys-Phe-DPen]OH (JOM-13). J. Med. Chem. 37, 4371-4383.

12. Mosberg, H.I., Omnaas, J.R., Lomize, A., Heyl, D.L., Nordan, I., Mousigian, C., Davis, P. \& Porreca, F. (1994) Development of a model for the $\delta$ opioid receptor pharmacophore: 2. Conformationally restricted $\mathrm{Phe}^{3}$ replacements in the cyclic $\delta$-receptor selective tetrapeptide Tyr-c [D-Cys-Phe-D-Pen]OH (JOM-13). J. Med. Chem. 37, 4384-4391.

13. Mosberg, H.I., Dua, R.K., Pogozheva, I.D. \& Lomize, A.L. (1996) Development of a model for the $\delta$ opioid receptor pharmacophore: 4 . Residue 3 dehydrophenyl-alanine analogs of Tyr-c[D-Cys-Phe-D-Pen]OH (JOM-13) confirm required gauche-orientation of aromatic side chain. Biopolymers 39, 287-296.

14. Lomize, A.L., Flippen-Anderson, J.L., George, C. \& Mosberg, H.I. (1994) Conformational analysis of the $\delta$ receptorselective, cyclic opioid peptide, Tyr-c[D-CysPhe-D-Pen]OH (JOM-13). Comparison of X-ray crystallographic structures, molecular mechanics simulations and ${ }^{1} \mathrm{H}$ NMR data. I. Am. Chem. Soc. 116, 429-436.

15. Ho, J.C. (1997) Development of a model for the $\delta$-opioid receptor pharmacophore. $\mathrm{PhD}$ thesis, University of Michigan, Michigan, USA.

16. McFadyen, I.J., Ho, J.C., Mosberg, H.I. \& Traynor, J.R. (2000) Modifications of the cyclic mu receptor selective tetrapeptide Tyr-c[D-Cys-Phe-D-Pen] NH2 (Et): effects on opioid receptor binding and activation. J. Pept. Res. 55, 255-261.
17. Fowler, C.B., Pogozheva, I.D., LeVine, H. III \& Mosberg, H.I. (2004) Refinement of a homology model of the $\mu$-opioid receptor using distance constraints from intrinsic and engineered zinc-binding sites. Biochemistry 43, 8700-8710.

18. Portoghese, P.S. (1993) Selective nonpeptide opioid antagonists. In: Opioid I. (Herz, A., ed.), p. 279. Springer-Verlag, Berlin, Germany.

19. Meng, F., Hoversten, M.T., Thompson, R.C., Taylor, L., Watson, S.J. \& Akil, H. (1995) A chimeric study of the molecular basis of affinity and selectivity of the kappa and the delta opioid receptors. Potential role of extracellular domains. J. Biol. Chem. 270, 12730-12736.

20. Metzger, T.G. \& Ferguson, D.M. (1995) On the role of extracellular loops of opioid receptors in conferring ligand selectivity. FEBS Lett. 375, 1-4.

21. Pogozheva, I.D., Lomize, A.L. \& Mosberg, H.I. (1998) Opioid receptor threedimensional structures from distance geometry calculations with hydrogen bonding constraints. Biophys. J. 75, 612-634.

22. Lomize, A.L., Pogozheva, I.D. \& Mosberg, H.I. (1999) Structural organization of G-protein-coupled receptors. J. Comput. Aided Mol. Des. 13, 325-353.

23. Poulsen, A., Bjornholm, B., Gundertofte, K., Pogozheva, I.D. \& Liljefors, T. (2003)

Pharmacophore and receptor models for neurokinin receptors. J. Comput. Aided Mol. Des. 17, 765-783.

24. Munshi, U.M., Pogozheva, I.D. \& Menon, K.M. (2003) Highly conserved serine in the third transmembrane helix of the luteinizing hormone/human chorionic gonadotropin receptor regulates receptor activation. Biochemistry 42, 3708-3715.

25. Strahs, D. \& Weinstein, H. (1997) Comparative modeling and molecular dynamics studies of the delta, kappa and mu opioid receptors. Protein Eng. 10, 1019-1038. 
26. Paterlini, G., Portoghese, P.S. \& Ferguson, D.M. (1997) Molecular simulation of dynorphin A- $(1-10)$ binding to extracellular loop 2 of the kappa-opioid receptor. A model for receptor activation. J. Med. Chem. 40, 3254-3262.

27. Subramanian, G., Paterlini, M.G., Larson, D.L., Portoghese, P.S. \& Ferguson, D.M. (1998) Conformational analysis and automated receptor docking of selective arylacetamide-based kappa-opioid agonists. J. Med. Chem. 41, 4777-4789.

28. Liu, D.X., Jiang, H.L., Shen, J.S., Zhu, W.L., Zhao, L., Chen, K.X. \& Ji, R.Y. (1999) Molecular modeling on kappa opioid receptor and its interaction with nonpeptide kappa opioid agonists. Zhongguo Yao Li Xue Bao 20, 131-136.

29. Lavecchia, A., Greco, G., Novellino, E., Vittorio, F. \& Ronsisvalle, G. (2000) Modeling of kappa-opioid receptor/agonists interactions using pharmacophore-based and docking simulations. J. Med. Chem. 43, 2124-2134. 3o. Iadanza, M., Holtje, M., Ronsisvalle, G. \& Holtje, H.D. (2002) $\kappa$-Opioid receptor model in a phospholipid bilayer: molecular dynamics simulation. J. Med. Chem. 45, 4838-4846.

31. Wan, X.H., Huang, X.Q., Zhou, D.H., Jiang, H.L., Chen, K.X. \& Chi, Z.Q. (2000) Building ${ }_{3} \mathrm{D}$-structural model of kappa opioid receptor and studying its interaction mechanism with dynorphin A(1-8). Acta Pharmacol. Sin. 21, 701-708.

32. Filizola, M., Laakkonen, L. \& Loew, G.H. (1999) 3D modeling, ligand binding and activation studies of the cloned mouse delta, $\mathrm{mu}$; and kappa opioid receptors. Protein Eng. 12, 927-942.

33. Sanchez, R., Pieper, U., Mirkovic, N., de Bakker, P.I., Wittenstein, E. \& Sali, A. (2000) MODBASE, a database of annotated comparative protein structure models. Nucleic Acids Res. 28, 250-253.

34. McFadyen, I.J., Schaefer, M.J., Ho, J.C., Omnaas, J.R., Sobczyk-Kojiro, K., Mosberg, H.I. \& Traynor, J.R. (2000) Tetrapeptide derivatives of DPDPE lacking an N-terminal tyrosine residue are agonists at the mu opioid receptor. J. Pharmacol. Exp. Ther. 295, 960-966.
35. Neilan, C.L., Husbands, S.M., Breeden, S., Ko, M.C., Aceto, M.D., Lewis, J.W., Woods, J.H. \& Traynor, J.R. (2004) Characterization of the complex morphinan derivative $\mathrm{BU}_{72}$ as a high efficacy, long-lasting mu-opioid receptor agonist. Eur. J. Pharmacol. 499, 107-111.

36. Güntert, P., Brawn, W. \& Wüthrich, K. (1991) Efficient computation of threedimensional protein structure in solution from NMR data using the program DIANA and the supporting programs CALIBA, HABAS and GLOMSA. J. Mol. Biol. 21, 517-530.

37. Pogozheva, I.D., Lomize, A.L. \& Mosberg, H.I. (1997) The transmembrane 7-alphabundle of rhodopsin: distance geometry calculations with hydrogen bonding constraints. Biophys. J. 72, 1963-1985. 